\title{
Beach Erosion and Consequential Impacts Due to the Presence of Harbours in Sandy Beaches in Greece and Cyprus
}

\author{
V. K. Tsoukala ${ }^{1}$ - V. Katsardi ${ }^{1,2}$ (D) $\cdot$ K. Hadjibiros ${ }^{3}$. \\ C. I. Moutzouris ${ }^{1}$
}

Received: 19 February 2015 / Accepted: 22 July 2015 /Published online: 1 August 2015

(C) Springer International Publishing Switzerland 2015

\begin{abstract}
Harbours with protruding breakwaters that are built on coasts cause alterations to the wave field, which attacks the coastline adjacent to the structures. As a result, sandy beaches often start eroding. Examples from Greece and Cyprus are presented, veryfying that the causes of the phenomenon, which are (i) the obstruction of longshore sand movement, and (ii) the longshore sand transport from the wave-action zone to the calm wave-shelter zone triggered by wave diffraction, work almost always simultaneously and none can be underestimated. A large discussion is held internationally indicating that although the construction of harbours is meant to enhance tourism and local economy, it very often leads to environmental and socioeconomic failure that are analysed in the present paper. In addition, the paper discusses the methods of beach protection in such cases and gives guidelines for following effective practices in Greece.
\end{abstract}

Keywords Beach erosion · Harbours - Diffraction - Marine environment - Environmental impacts - Socio-economic impacts

\section{Introduction}

Beach erosion is due to wave action. However, other causes such as the decrease of fluvial sediment supply caused by the construction of dams (see for example Velegrakis et al. 2008)

\section{K. Tsoukala}

tsoukala@mail.ntua.gr

1 Laboratory of Harbour Works, School of Civil Engineering, National Technical University of Athens, 15780 Zografos, Greece

2 Department of Civil Engineering, University of Thessaly, 38334 Pedion Areos, Volos, Greece

3 Department of Water Resources and Environmental Engineering, School of Civil Engineering, National Technical University of Athens, 15780 Zografos, Greece 
and the sea-level rise caused by climate change (see for example Fröhle et al. 2011) are increasingly important. However, the rapid disappearance of sandy beaches during the last 30 years in coasts and beaches worldwide cannot be solely explained by the above, and are, therefore, associated with human activities in coastal areas, such as the contstruction of new harbours in order to serve growing needs for fishing and/or, in the case of touristic areas, marinas. For example, overpopulation in Japan has led to a construction of about 2000 fishing ports in a coastline of about $30,000 \mathrm{~km}$ (CIA World FactBook). This means one fishing port every $15 \mathrm{~km}$ of coatline, inevitably affecting the coastal area. Similarly, in areas where tourism is largerly associated with the local economy, such as the Mediterrenean, marinas and other leisure coastal structures are added to the fishing ports and the commercial ports, again leading to a deterioration of the coastal area. For example, Croatia has $5835 \mathrm{~km}$ of coastline and 107 marinas. This means one marina every $54 \mathrm{~km}$, while Greece, with the longest coastline in Europe $(13,676 \mathrm{~km})$, has a total of more than 1000 harbour facilities, meaning one coastal structure every $13 \mathrm{~km}$. This large number of coastal structures, when built in sandy beaches, leads inevidably to beach erosion. In the case of extensive coastlines, erosion could be one of the most significant socio-economic problems, requiring the attention of states and local authorities, as its impacts may be extended kilometres alongshore and sometimes with transboundary implications. On the other hand, in the case of pocket beaches, most of the times the coastal erosion is a local phenomenon with pressures and impacts on the residents of a nearby town and/or the tourism industry (Özhan 2002).

Human-induced coastal erosion in Europe exceeded coastal erosion driven by natural factors, according to Erosion's reports (Eurosion 2004a; 2004b). Coastal erosion mainly derives from the direct and indirect impacts due to: a) the construction of harbours, tourism and leisure facilities as well as hard coastal defence structures, b) land reclamation, c) river water regulation works, d) dredging, e) vegetation clearing f) gas mining or water extraction, g) ship-induced waves, etc.

Particularly, ports and harbours with protruding breakwaters built on a coast cause alteration to the wave field, which attacks the coastline adjacent to the structures and changes the flow of sediments along the shore. As a result, sandy beaches often start eroding and run-up in coasts with cliffs increases significantly (see, for example, Moutzouris 2010; Koufali et al. 2014; Uda 2010; Katsardi et al. 2014). To avoid the undesirable possible effects, the justification for the extent of potential impacts and a plan to mitigate such effects must be fully considered during the site allocation and the design process of the harbour.

The two most important questions related to the effects on adjacent or nearby coasts that must be addressed in a harbour's design are as follows: a) will the proposed structures sufficiently change the direction or magnitude of wave energy at an adjacent or nearby property to adversely affect the shore? and b) will the project change the flow patterns, interrupt or entrap sufficient littoral material to create a deficit of beach material, and increase erosion along the shore on nearby properties?

A large discussion has begun recently because, although the construction of harbours is meant to enhance tourism and local economy, it very often leads to environmental failure with socio-economic impacts such as the complete disappearance of a sandy beach or the severe change on the morphology of the beach by the forced design of protecting constructions that create environmental nuisance, having at the end negative impacts on both tourism and economy. Also, as extensively discussed in Eurosion (2004a), an immediate impact of coastal erosion is coastal flooding, that is associated with the loss of lands but also has ecological consequences (Fig. 1). 


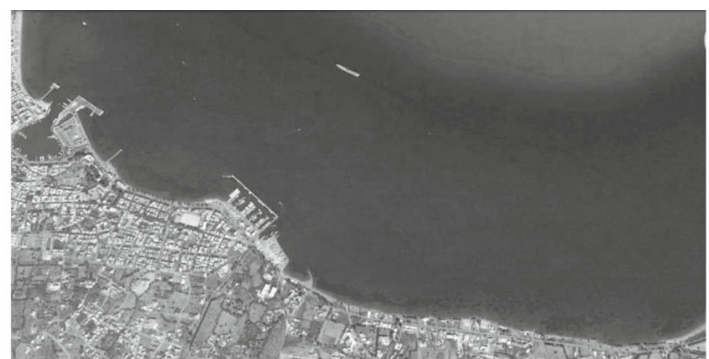

(a) Source: "Kos" $36^{\circ} 53$ ' 32.72 ” N and " $27^{\circ} 18^{\prime} 32.84$ ” E. Google Earth, October 9, 2013. July 2, 2015

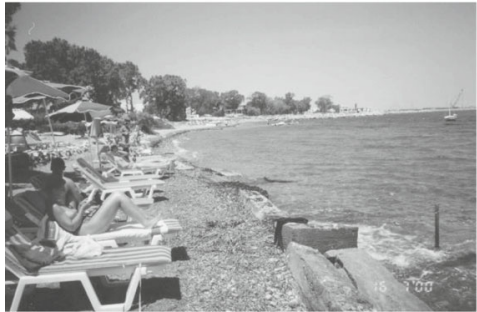

(b)

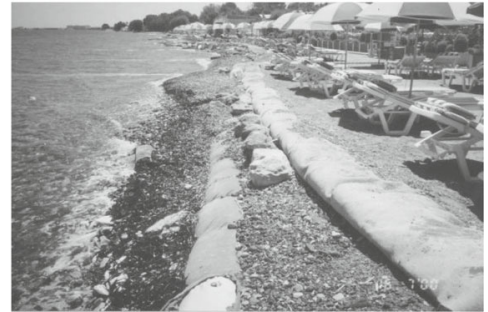

(c)

Fig. 1 Significant beach erosion due to the presence of a marina in Kos

In the present work, the environmental and socio-economic impacts concerning the interaction of harbours with their adjacent coasts are revisited; in particular, beach erosion examples are analysed in sandy coasts in Greece and Cyprus, where as discussed earlier, the construction of coastal structures is associated with tourism and hence the economy. The paper is enhanced by the presentation of part of an on-going experimental and numerical work that studies the impact of the presence of a harbour and, specifically, how both the geometrical characteristics of the harbour and the nature of the incident waves affect the adjacent beach. Also, a methodology for managing environmental impacts is presented taking into account the existing national legal framework on the prior identification. Finally, some examples from Greece and Cyprus are given presenting mitigation measures taken based on the experience and technical expertise of the Laboratory of Harbour Works (LHW) in NTUA.

\section{Impacts Due to the Interaction of Harbours with their Adjacent Coasts}

\subsection{Disruption of Long-Shore Drift and Modification of Wave Propagation Patterns - Flooding}

The reason for the change in the morphology of a sandy beach around a harbour is twofold. First, with the construction of the harbour an obstruction of longshore sand movement is created. This is because any structure on a sandy beach interrupts the so called longshore currents that are generated when waves that propagate at an angle break. As expected, these currents are responsible for transporting sediments alongshore and hence their obstruction leads to the accretion upstream and to erosion downstream. This problem is easily spotted, and it is more often met in long beaches (see e.g. Fig. 2) rather than in pocket beaches where the sediment budget is smaller. 


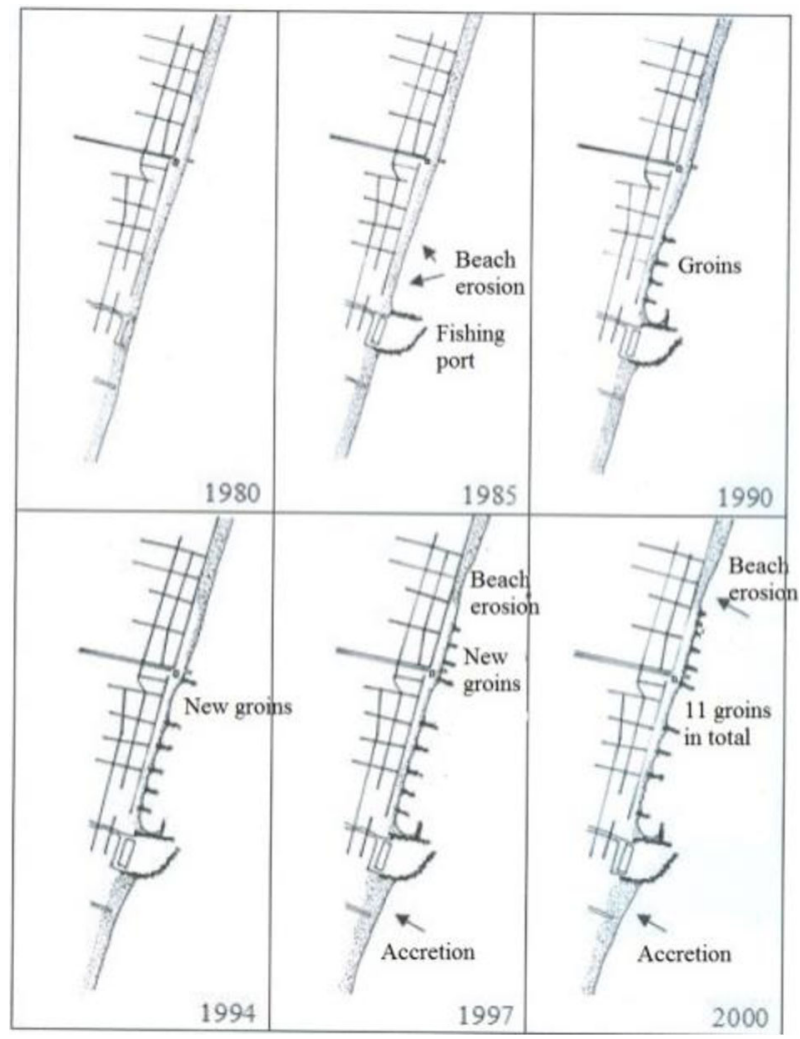

Fig. 2 Series of coastal structures to protect from beach erosion caused by the presence of a small port in Katerini beach, Greece (Anagnostou et al. 2010; Kombiadou et al. 2012)

Second, hard windward surface-piercing structures, associated with harbour construction, lead to wave diffraction, which is the alteration of the wave crest direction. Therefore, the harbour's breakwater creates two wave zones: a calm wave zone downward of the breakwater, the so called wave-shelter zone by Uda (2010), and a wave-action zone. Both zones are noted in Fig. 3 and are affected by the wave diffraction due to the presence of the harbour. In the coast downstream of the harbour, the wave direction, and hence the wave-induced longshore currents, change from outside to inside the wave-shelter zone due to diffraction. As a result, longshore sand transport towards the calm zone will be induced, resulting in erosion in the wave-action zone and accretion into waveshelter zone. Moreover, the much reduced wave-heights in the calm wave-shelter zone prevent the creation of an outward longshore current and hence the loss of the original beach topography equilibrium is permanently lost. This mechanism is enhanced by the fact that the alteration in wave direction due to wave diffraction and refraction, leads to a concentration of wave energy in areas where, before the construction of the structure, it was absent. This amplification is weaker for random waves and stronger for regular waves (see, for example, Goda 2010) and, depending on the wave direction, it can reach $15 \%$, leading to larger longshore currents towards the waveshelter zone and thus accelerating the erosion-accretion mechanism caused by wave-sheltering. This increase in the wave height, although has been theoretically shown by Penny and Price (1952) and plotted in the Wiegel diagrams (1962), refers to uniform bed slope and is sometimes underestimated when designing harbours in sandy beaches. 


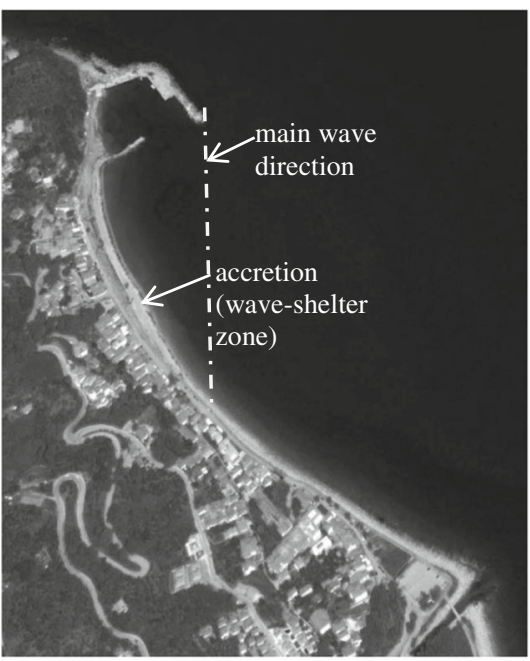

(a)

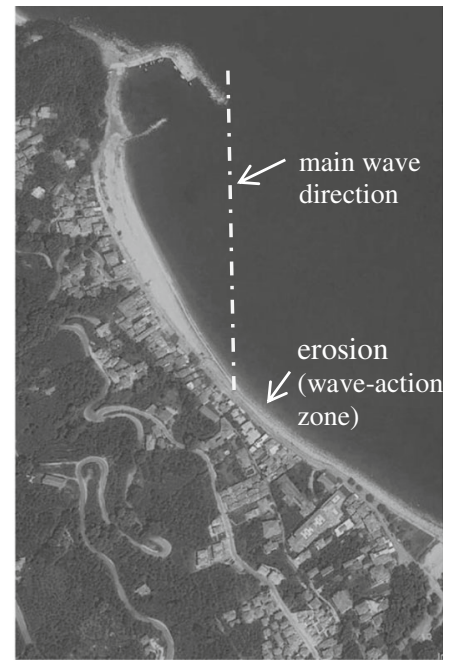

(b)

Fig. 3 Beach erosion due to the presence of the port at Ag. Ioannis, Pilio, Greece, in 2012 and 2013 at (a) and (b) respectively, Source: "Ag. Ioannis, Pilio" 39 $25^{\prime} 13.19^{\prime}$ N and " $23^{\circ} 09^{\prime} 27.19^{\prime}$ E. Google Earth, April 9, 2012(a) and April 22, 2013 (b). July 2, 2015

After the numerous field examples given by Moutzouris (2010), two of which are presented herein in Figs. 3 and 4, the relevant beach erosion problems given by the 2004 EU guide (Eurosion 2004a; 2004b), and the extended research of relevant problems associated with the construction of wave-shelter harbours in Japan (Uda 2010), the diffraction-associated factors of beach erosion cannot be overlooked when designing harbours in sandy beaches.

\subsection{Numerical and Experimental Investigation}

In the framework of this work, an ongoing research is carried out at the LHW of NTUA (for example Katsardi et al. 2011) to provide guidelines for the optimisation of harbours' layouts in order to eliminate erosion effects due to the wave energy intensification at the adjacent beaches. Indeed, the phenomenon of wave amplification has been examined with real sea-states using a Boussinesq wave model, and specifically, the enhanced equations proposed by Madsen and Sørensen (1992) through the DHI 2007 MIKE21-BW platform. A simple layout of a semiinfinite, finite-width, breakwater is placed on a mild and constant bottom slope beach; the main axis of which being parallel to the depth contours. The $12,000 \mathrm{~m} \times 12,000 \mathrm{~m}$ area has a largest water depth of $13.2 \mathrm{~m}$ gradually reducing to a fully absorbing beach. The interest of the present study is focused on the downstream area of the breakwater. This is indicated as area "D" in Fig. 5a, b. The incident waves enter from the left part of the area which coincides with the largest depth. They are linear (wave steepness $H / L<0.008$ ), both regular and random, with or without directionality, propagating towards the semi-infinite breakwater with various angles. The results presented in Fig. 5 are contour plots of the ratio $H / H$ (without bw) where $H$ is the wave height with the breakwater presence and $H_{\text {(without bw) }}$ is the wave height without the breakwater presence; directly calculating the effect of the breakwater in wave action amplification. Also, $T$, $H_{s}$ and $T_{p}$ are the wave period, the significant wave height and the period corresponding to the 

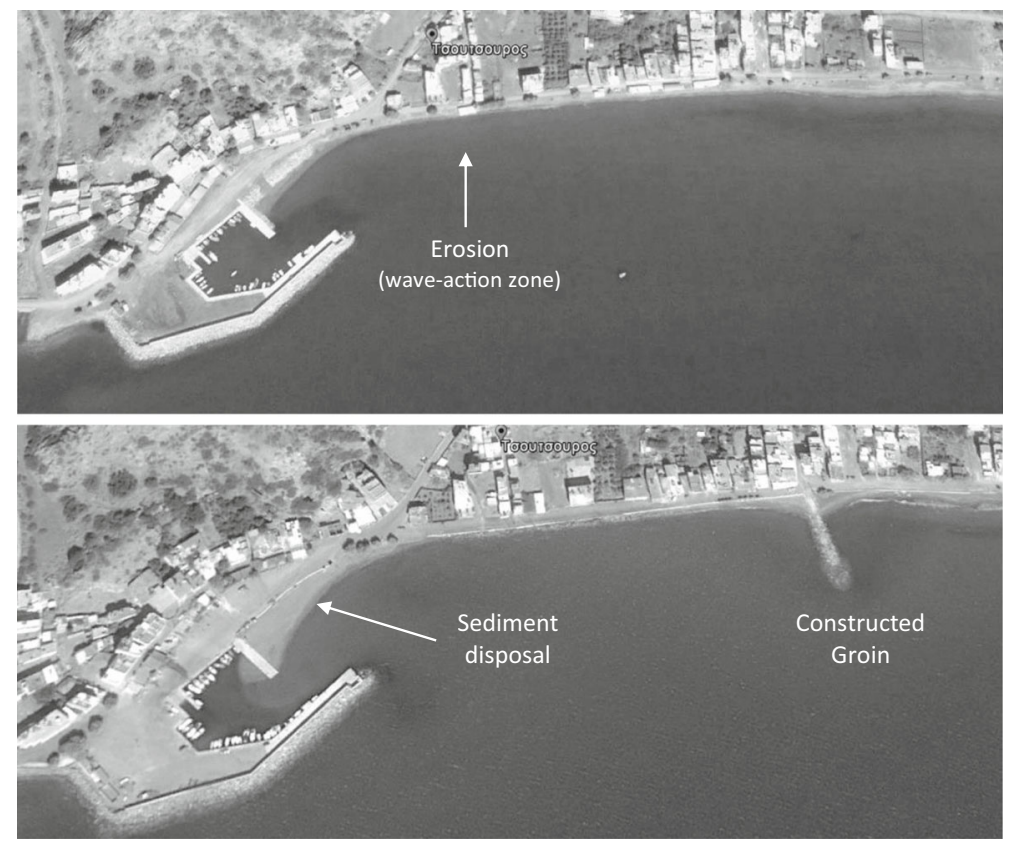

Fig. 4 Beach erosion at the adjacent coast of the harbour due to the intensification of diffracted waves in Tsoutsouros, Heraklion, Greece, before (2006) and after the construction of a groin for coastal protection in 2013 at (a) and (b) respectively Source: "Tsoutsouros Heraklion" 34 59'03.99” N and "25 17'25.92" E. Google Earth, October 19, 2002 (a) and August 8, 2013 (b). July 2, 2015

spectral peak for random JONSWAP waves, respectively, $a_{o}$ is the incident wave angle, $\theta$ is the angle of directional spread and $\gamma=3.3$ is the peak enhancement factor for the unsteady waves. In all cases, the wave action amplification in area " $\mathrm{D}$ " is verified (values of $H / H$ (without bw) $>1$ ) and concentrated immediately downstream of the wave-shelter zone, dispersing further downstream. This inevitably will have serious implications in beach erosion. In particular, the wave height is amplified by more than $10 \%$ for steady waves propagating on a $120^{\circ}$ towards the breakwater (Fig. 5a) and by $15 \%$ for steady waves perpendicular to the breakwater (Fig. 5b). When unsteadiness is introduced, the increase in wave action is larger ( $20 \%$ - Fig. 5c). Finally, for unsteady directional waves this increase reduces somewhat to $18 \%$ and this is expected as the wave energy is more dispearsed due to the small directional spread.

Furthermore, a physical model of a typical breakwater has been constructed in one of the three 3-D wave basins of LHW of NTUA (Fig. 6a) at a 1:100 scale (Koufali et al. 2014). The bathymetry of the sandy area is mild except for the interior of the harbour where it is held constant at $-3 \mathrm{~m}$. Measurements of unidirectional unsteady wave crest elevations have been conducted for 3 different layouts, each one extending the windward breakwater, and thus, increasing the wave-shelter area, as shown in Fig. 6b. Through these measurements, the formation of the wave-shelter and wave-action zone has become profound. In particular, the wave probes, that were in the wave-shelter zone, measured always reduced wave heights compared to the wave probes in the wave-action zone as expected. However, what was mostly interesting is that the probes, that were immediately out of the shelter zone, measured increased wave heights compared to the probes that were further downstream for all the layouts examined. For example, for layout 2, and for waves propagating perperdicular to the depth 
(a) $H=0.5 \mathrm{~m}, T=7 \mathrm{~s}, \alpha_{o}=120^{\circ}$

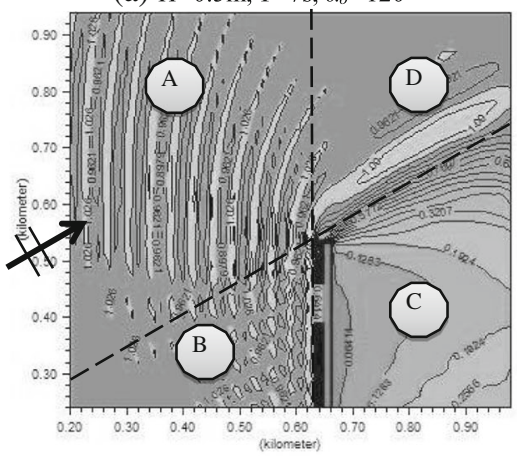

(c) $H_{s}=0.5 \mathrm{~m}, T_{p}=7 \mathrm{~s}, \alpha_{0}=90^{\circ}, U D$

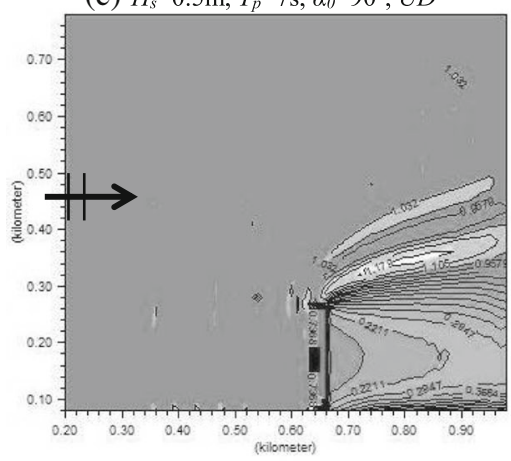

(b) $H=0.5 \mathrm{~m}, T=7 \mathrm{~s}, \alpha_{0}=90^{\circ}$

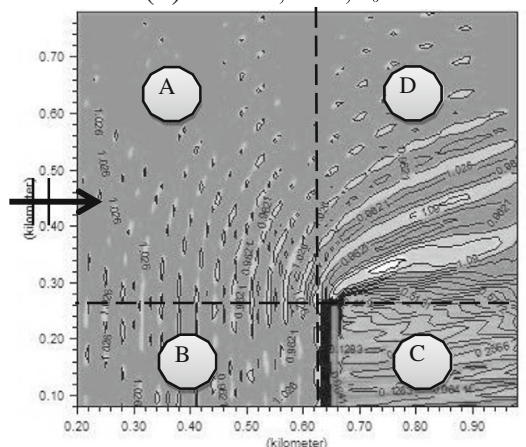

(d) $H_{s}=0.5 \mathrm{~m}, T_{p}=7 \mathrm{~s}, \alpha_{0}=90^{\circ}, \theta=10^{\circ}$

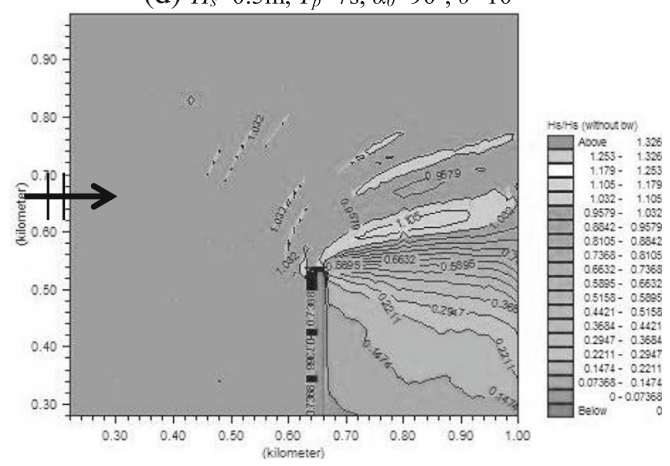

Fig. 5 Increase of incident wave height with the presence of a semi-infinite breakwater; (a) and (b) Regular Waves; (c) and (d) Random Waves

contours, wave probes 1 and 2, that are in the wave-shelter zone, show the smallest wave heights, as it is expected, and probes 3 and 4, that are immediately out of the wave-shelter zone, the largest. The latter is consistent with the findings discussed earlier refering to Fig. 5. Accordingly, for layout 3 the largest wave heights occurred in probes 5 and 6 . This also means that the consecutive extensions of the breakwater displaced the increased waveheights

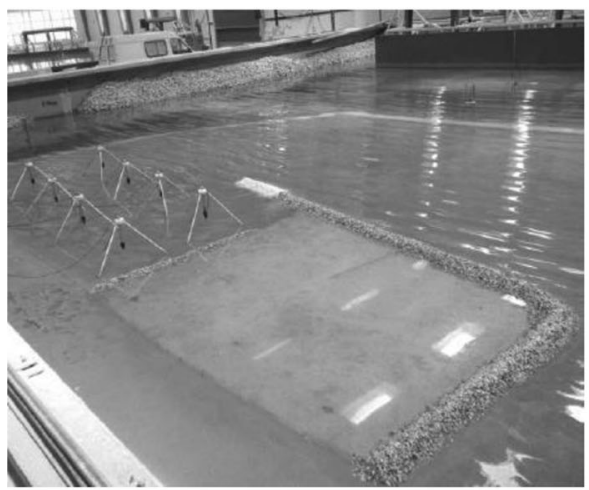

(a)

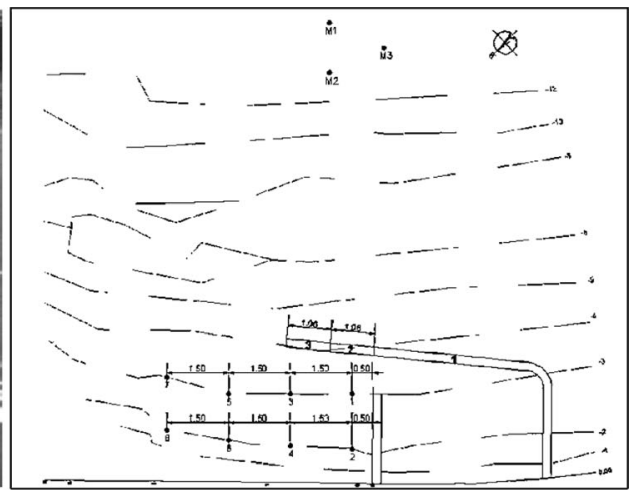

(b)

Fig. 6 Three different layouts of a physical model with a variable length of the windward breakwater 
downstream of the harbour. In more non-linear waves, this action is accompanied by a secondary amplification near the coastline, which is by no doubt responsible for beach erosion. Similar results have been verified in Giantsi and Moutzouris (2010).

The research team also investigated the above layouts numerically, again through the DHI 2007 MIKE21 platform, through the PMS, HD and ST modules, in order to understand the effect of the construction on the sandy beach. The above well-known and widely used modules are a wave module based on the Parabolic Mild Slope equation, a Hydrodynamic module that calculates the wave-induced currents based on the radiation stresses and a cohesive Sediment Transport module based on the calculated currents, respectively. In particular, in Fig. 7a it is shown that the direction of the wave-induced currents downstream of the structure change with the appearence of the structure. Furthermore, this change is enhanced with the consecutive extensions of the breakwater accompanied by strong turbulence. Moreover, it is shown how wave-diffraction is the governing mechanism of this change. This is also imprinted in Fig. $7 b$ where a trend of erosion is shown downstream of the harbour, concentrated where the wave height is amplified, and a trend of accretion is seen upstream of the structure. More details on this research can be found in Afentoylis (2013).

As discussed in Section 1, the numerical and experimental examples presented in Figs. 5, 6 and 7 is part of an ongoing research. Only part of this research is presented here in order to raise the effect of structures on sandy beaches.

\subsection{Modification of Soil-Weathering Properties}

While the shoreline vegetation protects the coasts naturally, effectively and inexpensively from erosion, the intensification of the wave action at the adjusted coasts because of the diffraction of waves on the protruding breakwaters could cause damage or total deforestation. Trees, on the other hand, offer excellent erosion control because of their deep roots, which bind the soil, and their leaves, intercepting rain before it impacts and erodes the soil. Conclusively, trees and
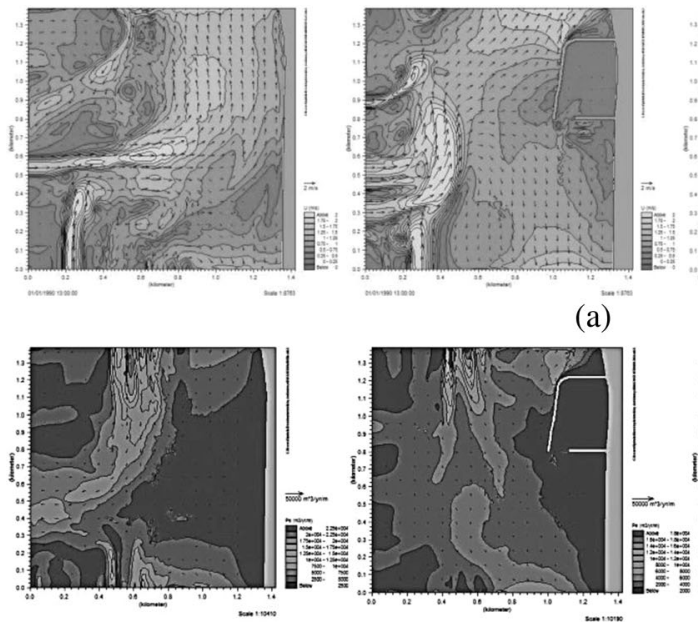

(b)

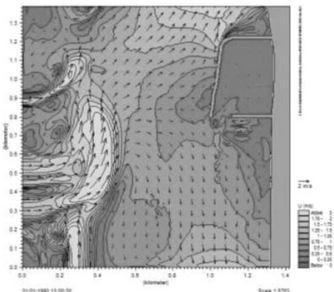

(a)
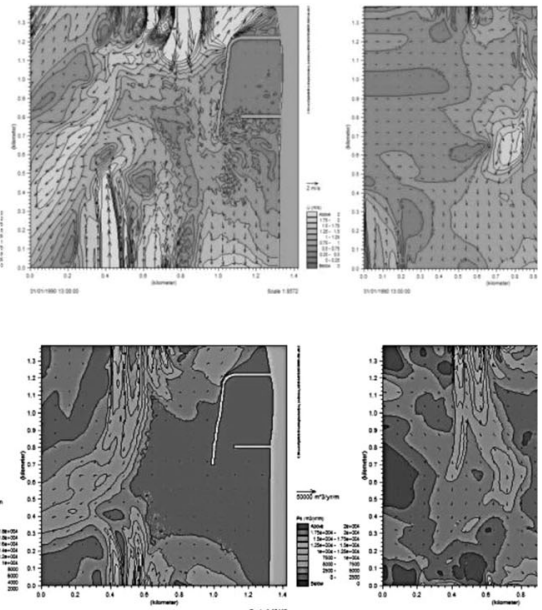

Fig. 7 Effect of a coastal structure on a sandy beach for four different structure layouts: (a) Velocities of waveinduced currents $(\mathrm{m} / \mathrm{s})$, (b) Mean annual sediment transport $\left(\mathrm{m}^{3} / \mathrm{yr} / \mathrm{m}\right) . a_{o}=90^{\circ}, H_{s}=3.20 \mathrm{~m}, T_{p}=8.53 \mathrm{~s}$ 
vegetation contribute to soil cohesion. Deforestation due to wave action and the induced erosion result in soil stability subversion and the expansion of landslide events especially along coastal cliffs.

\subsection{Ecological Impacts}

The construction and operation of any coastal structure is expected to cause environmental and socio-economic impacts. The separation of these effects to those caused by erosion and changes in hydrodynamic characteristics in the adjacent coasts seems to be a rather difficult and challenging task.

Although, several researches have been conducted and published on the variation in coastal processes due to the construction of a harbour (e.g., wave regime, alteration of hydrodynamics, sediment dynamics, depositional processes and geomorphologic impacts), the ecological impacts of these processes have not been sufficiently addressed.

The ecological impacts of a harbour construction are not only restricted locally on the adjacent coasts but are often dragged to the surrounding areas and gradually affect the coastal ecosystems at a regional scale (OSPAR Convention 2009). It is true that because of the variability of each ecological system, it is not easy to predict quantitatively these impacts of coastal structures, due mainly of their synergetic nature as well as their unknown and not easily predictable interaction in the long term between the two merged ecosystems - inland and marine - in the coastal zone. Some characteristic expected ecological impacts due to the presence of coastal structures are (Airoldi et al. 2005):

- the loss of coastal habitats,

- the reduction in biological productivity and biodiversity (Dugan et al. 2003; Dugan et al. 2011),

- the local increase in diversity due to colonization of the armor layers of the harbour breakwaters by algae and epibenthic fauna, which, however, may favor other species from the ones that existed previously in the area of the structure leading to a disruption of the ecological balance (OSPAR Convention 2009; Airoldi et al. 2005; Bacchiocchi and Airoldi 2003; Bulleri 2005; De Wolf 2001; Engledow et al. 2001; Martin et al. 2005; Moschella et al.2005),

- the attraction and prevalence of new fauna and avifauna from the increase of algae and epibenthic fauna (Walker et al. 2008), and

- the exploitation of coastal structures by certain species (e.g., mussels, octopuses, sea urchins, etc.) as a nest.

On the other hand, an adverse effect of the sediment accumulation on the lee side of the structure will probably cause a significant reduction in the abundance of benthic invertebrates (Martin et al. 2005).

Finally, a generally negative impact at a regional scale may occur if the construction of a harbour would be at a coast where a significant number of artificial hard coastal structures already exists in proximity, and therefore, the total system could disrupt natural barriers to species' distribution (Airoldi et al. 2005; Bulleri and Airoldi 2005; Glasby et al. 2007; Palumbi 2003). 


\subsection{Socio-economic Impacts}

As metioned before, beach erosion affect significantly the coastal habitats, with social and economic impacts on coastal communities (Bijlsma et al. 1995; Turner 2003). There are three obvious concequences from the latter: the aforementioned increase in the frequency of coastal flooding; the water supply shortage; and the space shortage or even complete loss of beaches.

Assessing the value of the socio-economic impacts is not a straightforward issue mainly because the economies of coastal areas show high vulnerability in the investors' preferences in the case of erosion and the subsequent degradation of the aesthetic environment (Nicholls et al. 2007; Nicholls 2011).

Generally socio-economic sectors that are affected and influenced from coastal erosion are: fisheries and aquaculture, recreation and tourism, biodiversity, settlements and infrastructure, financial services and human health.

The induced erosion of the adjacent coast of a harbour is affecting coastal economies in different degrees depending on the special condition of each region. The erosion could damage properties as well as touristic and urban infrastructure, leading to the deterioration of the coastal landscape and finally the devaluation of the touristic product (Espinosa 2011). It is, therefore, clear how crucial it is for countries whose economy is based on the development of the coastal zone to protect their beaches.

In order to quantify socio-economic impacts, suitable indicators (Bowen and Riley 2003) such as population dynamics, economic and social conditions, cultural traditions, habitat changes, land uses, human activities etc., must be chosen and models such as Pressure State Response (PSR) or Driving force, Pressure, State, Impact, Response (DPSIR) (OECD 1993; USED 1996) should be implemented.

\subsection{Indirect Impacts}

Indirect effects include increased shipping activities, with emissions and the introduction of invasive alien species, being consequent environmental impacts and an increase in tourism, with an attendant increase in wastes.

\section{Mitigation Measures of Coastal Erosion}

Erosion adjacent to the harbour coasts can be reduced either by limiting the amount of sand that is trapped by a structural field and allowing sand movement past the field or by limiting the wave energy, which dissipates after the wave diffraction, on the protruding breakwaters of the harbour.

Measures that are commonly employed to mitigate downdrift erosion include the following:

- $\quad$ prefilling with sand

- permeable and low-profile structures where the harbour's operation is not disturbed

- $\quad$ series of groins along the downdrift beach

- detached breakwaters along the downdrift beach

- submerged breakwaters along the downdrift beach

- floating breakwaters

- modification of the harbour's layout in order to achieve minimum erosion (e.g., changes in the angle and the length of the protruding breakwaters) 
Downdrift coasts can be prefilled to counter the expected increase in erosion caused by the harbour. In cases where the downdrift erosional effects cannot be avoided, prefilling downdrift beaches could be done with the first nourishment and repeated as needed based on monitoring results and sediment budget analysis, which may include numerical modelling.

The negative impacts of coastal structures can be reduced if some sand is allowed to move over (low profile, submerged), through (permeable) or under (floating) them. Permeable breakwaters allow sand to move through holes or gaps in the structure as well as around the seaward ends of these structures but can be only applied when the wave action is not severe.

As for the adjusting beach, the most economical ways of protecting beaches that suffer from erosion is armouring the coast with natural rocks. This solution, although it is easy, low-cost and permanent, is not recommended for areas where the sandy beach is a tourist attraction of the area.

When the target is to retain the nature of the sandy beach then one of the most common ways of protecting the beach is to construct a series of groins or breakwaters downstream of the harbour in the wave action area. While a series of groins (e.g., Figs. 2a and 8) trap or accumulate sediments which would otherwise drift along the longshore currents, within their limits, detached breakwaters reflect and dissipate some of the incoming wave energy, which reduces wave heights in the lee of the structure and reduces the magnitude of littoral transport within the protected area. This reduction of littoral transport can stabilize or reduce the erosion of the adjacent beach. In Figs. 9 and 10, two successful examples of this application are presented, whose design was held in the LHW of NTUA (Anastasaki and Moutzouris 1999; Giantsi and Papathanassiou 2006). Similar to surface piercing breakwaters, submerged breakwaters can potentially create a lower-energy zone where littoral transport and erosion are reduced. An advantage of submerged breakwaters is the potential of achieving erosion control with a structure that does not obstruct the view of the water or the horizon. Submerged breakwaters may also provide hard bottom habitat, which could mitigate impacts to the environment where nearshore rock outcrops may be affected by the project (Everts Coastal 2000). Indeed, beach rocks that have been formatted in beaches across the Mediterranean work as natural submerged breakwaters and 'lock' the beach profile modifying the hydrodynamics of the beach and affecting both long and cross-shore sediment transport (Vousdoukas et al. 2007).

However, the effect of climate change which leads to sea-level rise leads into further impacts into the coastal defense structures (Karambas 2014) and should be also taken into account. Moreover, these measures do not provide always a secure and permanent solution. In

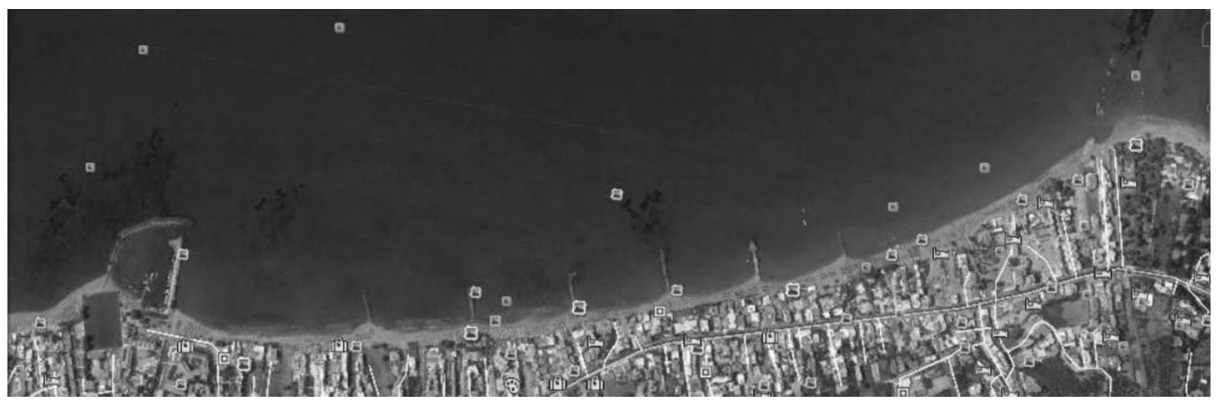

Fig. 8 Series of groins to protect from beach erosion downdrift of small port in Ag. Marina, Chania, Greece,

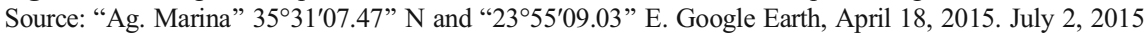




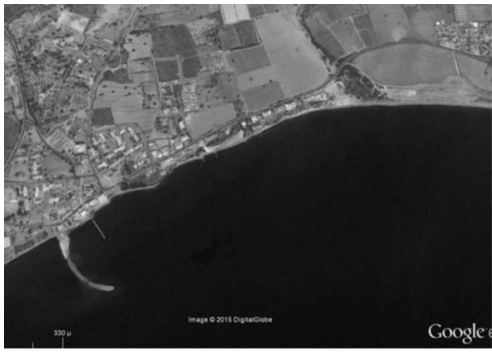

(a)

Source: "Zygi, Larnaka, Cyprus". $34^{\circ} 43^{\prime} 45.99^{\prime \prime} \mathrm{N}$ and " $33^{\circ} 20$ ' $49.15^{\prime}$ " E. Google Earth, June 9, 2013. July 2, 2015

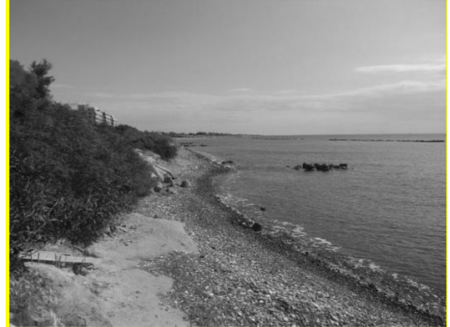

(c)

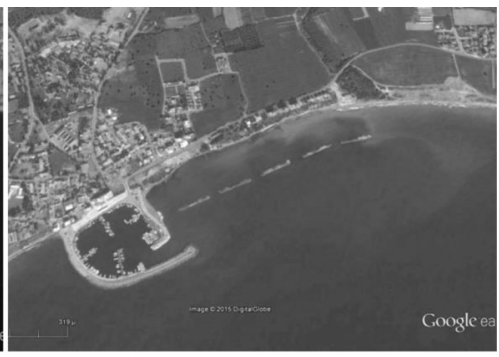

(b)

Source: "Zygi, Larnaka, Cyprus". $34^{\circ} 43^{\prime} 45.99^{\prime}$ " $\mathrm{N}$ and " $33^{\circ} 20^{\prime} 49.15^{\prime}$ " E. Google Earth, June 9, 2013. July 2, 2015

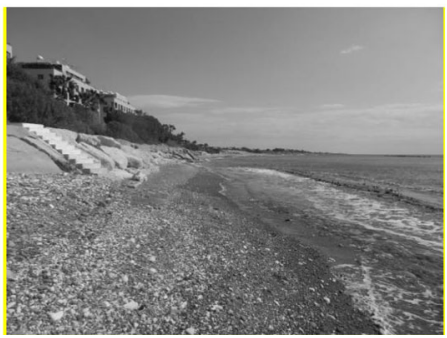

(d)

Fig. 9 Series of protecting breakwaters, constructed downstream of the expansion of a small port at Zygi Kiti, Cyprus to prevent beach erosion. Note the effectiveness before (2009) and after (2011) the new works constructed in (c) and (d), respectively

Fig. 11, it is shown that the small beach on the west of the small harbour in Kato Pyrgos in Cyprus did not seem to have reached a stable form before 2010, where the 5 groins that had been constructed along with the port only shifted the erosion further downstream, as also seen in the example of Katerini beach (Fig. 2), and natural rocks have been used to protect the beach. Therefore, a new series of groins and breakwaters were proposed and constructed in 2010 to protect more effectively the adjacent beach. Specifically, 4 new breakwaters and a series of five short groins ( $15 \mathrm{~m}$ long) were constructed to treat beach erosion (Tsoukala et al. 2010). The success of the new design is monitored in Figs. 11b, c. Also, the new design included an $80 \mathrm{~m}$ extension of the windward eastern mole and construction of a parallel breakwater in order to enhance the navigation conditions in the entrance of the port and to reduce the quantity of dead sea-grass entering the port.

A more complex and environmental friendly solution is using the material that deposits at the accretion area for beach nourishment of the erosion area, sometimes in combination with the construction of some protective works as the ones mentioned above, especially when the recession of the coast is very extended. However, it should be noted that the nourished material is far more rapidly washed away compared with the stage when the beach erosion was triggered, because the steepening of the beach slope has made the beach stability more vulnerable (Uda 2010). This problem is yet to be addressed.

In any case, the best way to protect beaches is to avoid constructing structures in areas where the risk of beach erosion is high. In effect, harbours should be avoided to be constructed in sandy beaches, especially in touristic areas. However, if this is unavoidable, the harbours must be designed by performing an early and thorough design investigation to show the possible effects of a new harbour on the adjacent beach environment. 


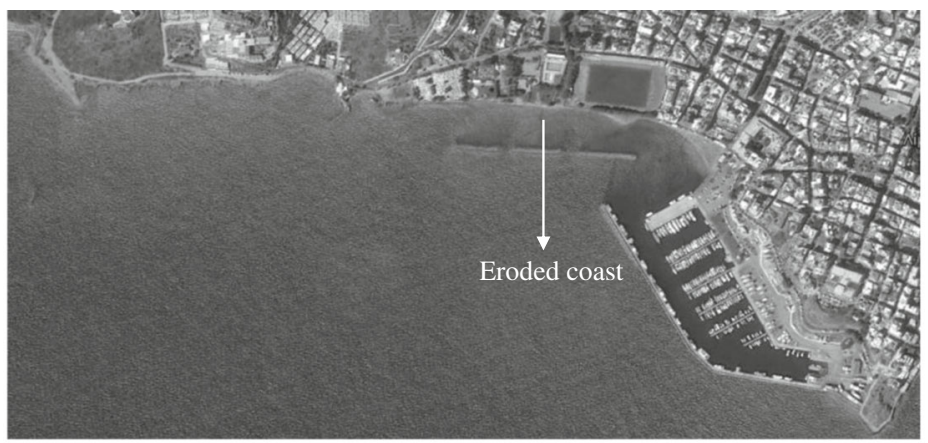

(a) Source: “Ag. Nikolaos, Lasithi”. 35'11'05.97” N and “2543'39.97” E. Google Earth, October 14, 2015. July 2, 2015

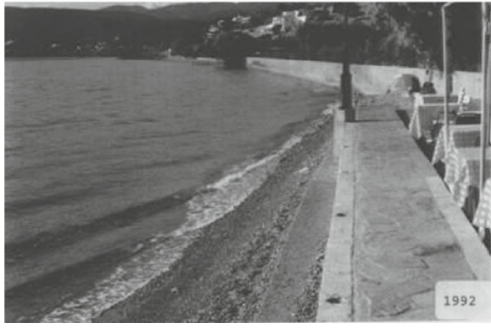

(b)

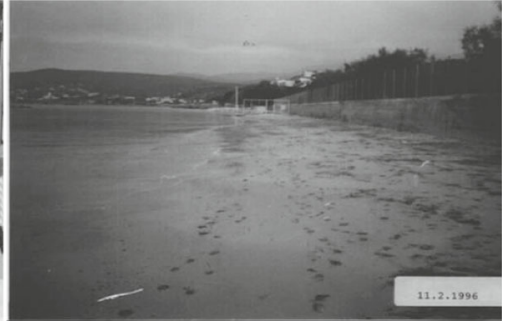

(c)

Fig. 10 Series of breakwaters constructed to protect from beach erosion downdrift of the marina in Ag. Nikolaos, Lasithi, Greece in (a). Views of the eroded coast are given before 1992 and after the construction of the structures in (b) and (c), respectively

\section{Guidelines for Erosion Mitigation and Control of Consequential Impacts}

In Greece, like in most of the EU, the technical and environmental regulation of a harbour construction is controlled by different administrative entities or institutions/ ministries in different contracting parties. Depending on the size and the type of each harbour (commercial, fishing, marina, etc.), the responsibilities are shared between national and regional authorities. Currently, the construction of harbour works refers to the national implementation of EC regulations, such as the Environmental Impact Assessment (EIA) Directive (Directive 85/337/EEC), Birds Directive (79/409/EEC) and Habitats Directive (92/43/EEC), and general ecological management principles that have systematically been incorporated into national law. In general, although their application is not very recent, the monitoring of the effectiveness of such directives is limited in terms of both the statistical data and the follow-up of their application.

In order to manage the complex and sometimes controversial environmental impacts concerning the interaction of harbours with their adjacent coasts, it is very important first to understand the hydrodynamic processes, and then, how these have influenced the historical development of the coast. The main underlying principles for the environmental impacts assessment and management in this case could include (NRC 1990; ARC 2000; Prasetya 2006; Fröhle and Kohlhase 2004): 


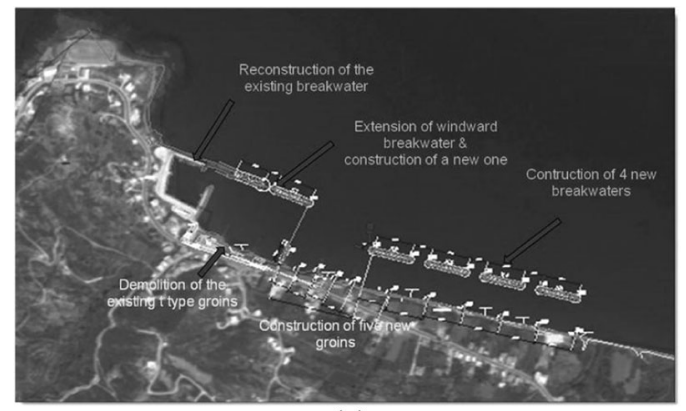

(a)

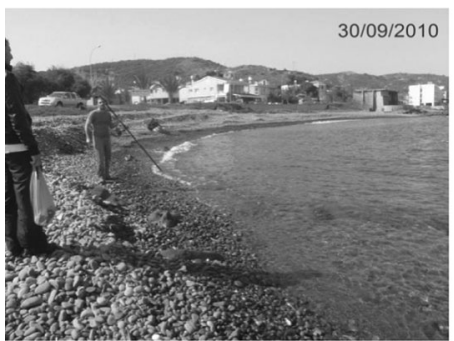

(b)

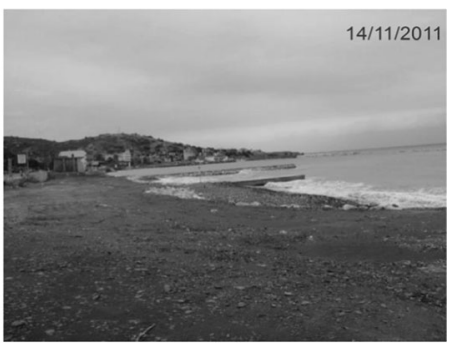

(c)

Fig. 11 Series of beach protecting projects (both groins and breakwaters) downstream of the small harbour in Kato Pyrgos, Cyprus. Note the effectiveness of the new works constructed in 2010 in (b) and (c)

- The identification and confirmation as a problem that the coastal erosion and/or coastal flooding concerning the interaction of harbours with their adjacent coasts exist in the area of interest.

- The identification and the quantification of the actual causes of the problem.

- The identification of environmental and socio-economic issues concerning the interaction of harbours with their adjacent coasts.

- The understanding of the key processes and of coastal dynamics characteristics as well as the system boundaries that reflect the natural processes of the erosion and/or flooding problem.

- The determination of the coastal erosion and flood protection measure options with careful evaluation of the effects on adjacent shores by the implementation of best practices through all the life cycle of the harbours (design, construction, operation and maintenance).

A committee was recently (October 2014) formed in the Greek Ministry of Public Works, in which members of the research team are participating, in order to address the matter of beach erosion. The committee, taking into consideration the severity and the consequences of beach erosion, especially in a country whose economy is based on tourism, is going to draw up specifications for the preparation of coastal studies which are expected to include measures in order to prevent beach erosion triggered by coastal structures by forcing to apply them a priori along with the siting and the design of harbours and not after the erosion problems have been recorded. These measures will hence hopefully lead to a more proper design of coastal structures in sandy beaches. 


\section{Conclusions}

Harbours with protruding breakwaters built in a coast cause alteration to the wave field, which attacks the coastline adjacent to the structures, and, as a result, sandy beaches often start to erode, and run-up in coasts with cliffs increases significantly. Coastal erosion is an inevitable (in the long run), gradual problem, with no easy answers. Except for the increase of flooding frequency from the sea, which results in the reduction of the beach's width, the beach erosion also leads to less space for recreational activities, with particularly consequences damaging to tourist areas. Besides, the reduction or the distraction of coastal ecosystems, the degradation of the coastal farmland, and the threat of the infrastructure are some of the most important environmental impacts because of the interaction of harbours with their adjacent coasts. All these adverse effects are detrimental both for coastal settlements and for the overall economy of a region.

Main reason for not taking action on the beach environment worldwide is politics. Ministries do not work together in such issues and do not want to state the reason for the problem because it is easier to get funds for natural disasters than for restoration work. Furthermore, the local residents always request urgent measures and hence fundamental measures are difficult to adopt. This leads to quick, low-cost constructions (e.g., with natural rocks), which produces rapidly an artificial coastline. Local authorities misconceive economic growth with new constructions though sometimes the best solution is the withdrawal of the harbour.

Acknowledgments An initial version of the paper has been presented in the 12th International Conference on Protection and Restoration of the Environment, Skiathos Island, Greece, June 29 to July 3, 2014.

\section{References}

Afentoylis V (2013) A numerical investigation of the of the influence of breakwater in wave action downstream of a harbour's protruding breakwater Diploma Thesis, national Technical University of Athens, School of Civil Engineering, http://hdl.handle.net/123456789/8207

Airoldi L, Abbiati M, Beck MW, Hawkins SJ, Jonsson PR, Martin D, Moschella PS, Sundelof A, Thompson RC, Aberg P (2005) An ecological perspective on the deployment and design of low-crested and other hard coastal defense structures. Coast Eng 52:1073-1087

Anagnostou Ch, Soukissian T, Chatzinaaki M, Antoniou P (2010) Impacts from the construction of a fishing port on the adjacent coasts in Paralia Katerinis (Greece): lesson to learn for an alternative design of coastal works. Proc of the 5thHellenic conference of harbour works, November 22-25, Athens, Greece, pp 229-238 (in Greek)

Anastasaki EN, Moutzouris CI (1999) Geomorphological change of the coast due to the construction of a system of three offshore breakwaters in Ag. Nikolaos of Crete, Proceedings of the 1st Hellenic Conference Management and improvement of coastal zones, November 22-25, Athens, Greece, pp 315-323 (in Greek)

ARC (2000) Auckland regional council, Coastal Erosion Management Manual Technical Publication No 130

Bacchiocchi F, Airoldi L (2003) Distribution and dynamics of epibiota on hard structures for coastal protection. Estuar Coast Shelf Sci 56:1157-1166

Bijlsma L, Ehler CN, Klein RJT et al. (1995) Coastal zones and small islands. Impacts, Adaptations and Mitigation of Climate Change: Scientific-Technical Analyses. Contribution of Working Group II to the Second Assessment Report of the Intergovernmental Panel on Climate Change. Eds Watson RT, et al. Cambridge University Press, Cambridge, UK, pp289-324

Bowen RE, Riley C (2003) Socio-economic indicators and integrated coastal management. Ocean Coast Manag 46:299-312

Bulleri F (2005) Role of recruitment in causing differences between intertidal assemblages on seawalls and rocky shores. Mar Ecol Prog Ser 287:53-64

Bulleri F, Airoldi L (2005) Artificial marine structures facilitate the spread of a non-indigenous green alga, Codium fragile ssp tomentosoides, in the North Adriatic Sea. J Appl Ecol 42:10631072

CIA World Factbook: Coastline. http:www.cia.gov/library/publications/the-world-factbook/fields/2060. Accessed 5 Jul 2015 
OSPAR Convention (2009) Assessment of the impact of coastal defence structures, Technical Report, ISBN 9781-906840-75-4 Publication Number 435/2009

De Wolf P (2001) Focus: strandhoofdenals studieobjecten van ingenieurs en biologen. Vliz Nieuwsbrief 5:3-8

Dugan JE, Hubbard DM, McCrary M, Pierson M (2003) The response of macrofauna communities and shorebirds to macrophyte wrack subsidies on exposed beaches of southern California. Estuar Coast Shelf Sci 58S:133-148

Dugan JE, Airoldi L, Chapman MG, Walker SJ, Schlacher T (2011) Estuarine and Coastal structures: environmental effects, a focus on shore and nearshore structures. In: Wolanski E, McLusky DS (eds) Treatise on Estuarine and Coastal Science, 8. Academic, Waltham, pp 17-41

Engledow H, Spanoghe G, Volckaert A, Coppejans E, Degraer S, Vincx M, Hoffmann M (2001) Research on (1) the physical characterization and (2) the biodiversity of groynes and other hard constructions along the Belgian coast: final report. Report 20:1-110

Espinosa H (2011) A propósito de la erosión de playas, Estos días, http://www.estosdias.com.mx/opinan/2011/ 07/02/a-proposito-de-la-erosion-de-las-playas. Accessed 2 Feb 2015

Eurosion (2004a) Coastal erosion - Evaluation of the need for action, Living with coastal erosion in Europe: Sediment and Space for Sustainability, PART IV: A guide to coastal erosion management practices in Europe Lessons Learned, B4-3301/2001/329175/MAR/B3, Directorate General Environment, European Commission

Eurosion (2004b) Coastal erosion - Evaluation of the need for action, Living with coastal erosion in Europe: Sediment and Space for Sustainability, PART V: Guidelines for incorporating coastal erosion issues into Environmental Assessment (EA) procedures,B5-3301/2001/329175/MAR/B3, Directorate General Environment, European Commission

Everts C (2000) Beach-retention structures and wide sandy beaches in Southern California. Shore Beach 68(3):11-22

Fröhle P, Kohlhase S (2004) The role of coastal engineering in integrated coastal zone management. Coastline Rep 2:167-173

Fröhle P, Schlamkow C, Dreier N, Sommermeier K (2011) Climate change and coastal protection: adaptation strategies for the German Baltic Sea coast. In: Schernewski G, Hofstede J, Neumann T (eds) Global change and baltic coastal zones. Springer, New York, pp 103-116

Giantsi ThE, Moutzouris CI (2010) Learning from the unsuccessful design of Kyparissia's harbour expansion. Proceedings of the 3rd international conference on the application of physical modelling to port and coastal protection, COASTLAB 2010, September 28 - October 1, Barcelona, Spain (e- proceedings)

Giantsi Th, Papathanassiou B (2006) Effects of crest elevation in shoreline evolution behind a system of detached breakwaters. First International Conference on the Application of Physical Modelling to Port and Coastal protection - COASTLAB 2006, Porto, Portugal, pp 555-560

Glasby TM, Connell SD, Holloway MG, Hewitt CL (2007) Non-indigenous biota on artificial structures: could habitat creation facilitate biological invasions? Mar Biol 151:887-895

Goda Y (2010) Random seas and design of maritime structures, 3rd edn. World Scientific, Singapore

Karambas TV (2014) Modelling of climate change impacts on coastal flooding/erosion, ports and coastal defence structures. Desalin Water Treat 54(8):2130-2137

Katsardi V, Tsoukala VK, Moutzouris CI (2011) Wave-action amplification, downstream of harbours, due to the presence of breakwaters. Proceedings of the 5th Hellenic conference of management and improvement of coastal zones, November 22-24, Athens, Greece pp 245-259 (in Greek)

Katsardi V, Tsoukala VK, Moutzouris CI (2014) Beach erosion due to the presence of harbours in sandy beaches: the case of Greece in comparison with international observations. Proceedings of the 12th International Conference on Protection and Restoration of the Environments, June 29th - July 3rd, Skiathos Island, Greece, (e- proceedings)

Kombiadou K, Krestenitis YN, Baltikas V, Kalantzi G (2012) Coastal Erosion Problems in Katerini: Methods and Measures. Protection and Restoration of the Environment XI, July 3-6, Thessaloniki, Greece, pp 758-767

Koufali M, Giantsi Th, Tsoukala VK, Moutzouris CI (2014) Experimental investigation of the influence of protruding structures on wave action downstream of harbours. Proceedings of the 12th International Conference on Protection and Restoration of the Environments, June 29th-July 3rd, Skiathos Island, Greece, (e- proceedings)

Madsen PA, Sorensen O (1992) A new form of the Boussinesq equations with improved linear dispersion characteristics Part 2: a slowly-varying topography. Coast Eng 18:183-204

Martin D, Bertasi F, Colangelo MA, de Vries M, Frost M, Hawkins SJ, Macpherson E, Moschella PS, Satta MP, Thompson RC, Ceccherelli VU (2005) Ecological impact of coastal defence structures on sediments and mobile infauna: evaluating and forecasting consequences of unavoidable modifications of native habitats. Coast Eng 52:1027-1051

MIKE21 DHI (2007). «MIKE 21, User Guide», Danish Hydraulic Institute, Water and Environment, Denmark 
Moschella PS, Abbiati M, Aberg P, Airoldi L, Anderson JM, Bacchiocchi F, Bulleri F, Dinesen GE, Frost M, Gacia E, Granhag L, Jonsson PR, Satta MP, Sundelof A, Thompson RC, Hawkins SJ (2005) Low-crested coastal defence structures as artificial habitats for marine life: using ecological criteria in design. Coast Eng 52:1053-1071

Moutzouris CI (2010) Protection of the coastline downstream of harbours due to wave action caused by breakwaters. Proceedings of the 5th Hellenic conference of harbour works, November 22-25, Athens, Greece, pp 199-212 (in Greek)

Nicholls RJ (2011) Planning for the impacts of sea level rise. Oceanography 24(2):144-157. doi:10.5670/ oceanog.2011.34

Nicholls RJ, Wong PP, Burkett VR, Codignotto J, Hay J, McLean R, Ragoonaden S, Woodroffe CD (2007) Coastal systems and low-lying areas. In: Parry ML, Canziani OF, Palutikof JP, van der Linden PJ, Hanso CE (eds) Climate change 2007: impacts, adaptation and vulnerability. Contribution of Working Group II to the fourth assessment report of the Intergovernmental Panel on Climate Change. Cambridge University Press, Cambridge, pp 315-356

NRC (1990) Managing coastal erosion, committee on coastal erosion zone management, water science and technology board, marine board, commission on engineering and technical system, national research council. National Academy Press, Washington

Organization for Economic Cooperation and Development (OECD) (1993) OECD core set of indicators for environmental performance reviews, Paris

Özhan E (2002) Coastal Erosion management in the Mediterranean: an overview, PAP-4/CE/02/PP.1, Priority Actions Programme, Regional Activity Centre, Ankara/Split, Turkey

Palumbi SR (2003) Population genetics, demographic connectivity, and the design of marine reserves. Ecol Appl 13:S146-S158

Penny WG, Price AT (1952) The diffraction theory of sea waves and the shelter afforded by breakwaters, Part I, In: eds. Martin JC, Martin WJ, Moyce WG, Penny AT, Price and C.K. Thornhill, Some gravity wave problems in the motion of perfect liquids. Philos. Trans. R. Soc. London, A(244):236-253

Prasetya G (2006) The role of coastal forests and trees in protecting against coastal erosion. http://www.fao.org/ docrep/010/ag127e/AG127E09. Accessed 2 Feb 2015

Tsoukala VK, Anastasaki EN, Moutzouris CI, Iakovou N, Zervos S (2010) Beach rehabilitation in Cyprus using environmentally friendly structures. J Mar Environ Eng 9(2):123-143

Turner RK (2003) Intergrated natural and socio-economic science in coastal management. Ocean Coast Manag $46: 447-460$

Uda T (2010) Japan's beach erosion: reality and future measures. World Scientific, Singapore

United States Agency for International Development (USAID) Performance monitoring and evaluation tips, No. 6, 1996. http://www.usaid.gov/pubs/-sourcebook/usgov/mfr.html

Velegrakis AF, Vousdoukas MI, Andreadis O, Adamakis G, Pasakalidou E, Meligonitis R, Kokolatos G (2008) Influence of dams on downstream beaches: eressos, Lesbos, Eastern Mediterranean. Mar Georesour Geotechnol 26(4):350-371

Vousdoukas MI, Velegrakis AF, Plomaritis TA (2007) Beach rock occurrence, characteristics, formation mechanisms and impacts. Earth-Sci Rev 85(1):23-46

Walker SJ, Schlacher TA, Thompson LMC (2008) Habitat modification in a dynamic environment: the influence of a small artificial groyne on macrofaunal assemblages of a sandy beach. Estuar Coast Shelf Sci 79:24-34

Wiegel RL (1962) Diffraction of waves by a semi-infinite breakwater. J Hydraulics Div ASCE 88(HY1):27-44 